\title{
st \\ Inconsciente, cérebro e consciência: reflexão sobre os fundamentos da metapsicologia freudiana
}

Fátima Caropreso

\begin{abstract}
电
RESUMO

No final do século xIx, quando Freud começou a perceber que a identificação entre o mental e a consciência era insuficiente para dar conta de uma série de fenômenos psíquicos, a psicologia era ainda, sobretudo, o projeto de uma ciência da consciência. As propostas de psicologia científica que surgem nesse período, como as de Brentano, Wundt e James, sustentavam a identidade entre o mental e a consciência e consideravam a existência de processos mentais inconscientes uma impossibilidade factual e teórica. Em primeiro lugar, este artigo se propõe a discutir a estratégia freudiana para introduzir a hipótese de um psíquico inconsciente em sua teoria metapsicológica. A seguir, analisa a justificativa dessa hipótese, tomando como base a reconstrução sistemática da argumentação freudiana proposta por Jerome Wakefield (1992). Por fim, comenta brevemente a relação entre os processos psíquicos conscientes e inconscientes, tal como ela se apresenta na metapsicologia freudiana, enfatizando como se constitui em uma de suas grandes dificuldades teóricas.
\end{abstract}

PalaVras-GhaVe • Freud. Metapsicologia. Inconsciente. Consciência. Processos cerebrais.

\section{INTRODUÇÃO}

O pensamento metapsicológico de Sigmund Freud consiste em uma reflexão que busca sistematizar os resultados da investigação psicanalítica e dar-lhes a forma de um sistema coerente e conceitualmente sólido. A metapsicologia representa, assim, um trabalho de demonstração, justificação e fundamentação das teses centrais da teoria psicanalítica. É a partir de tal reflexão que podemos compreender qual seria, para Freud, a natureza dos processos psíquicos, quais seriam as leis que regeriam o seu funcionamento e que estariam na base de suas manifestações normais e patológicas. Neste artigo, pretendemos, primeiramente, a partir da teoria metapsicológica freudiana, retomar a estratégia utilizada pelo autor para introduzir em sua teoria a hipótese de um psiquismo inconsciente e, em seguida, analisar globalmente a justificativa para a 
introdução dessa hipótese. Por fim, comentaremos brevemente de que maneira a relação entre os processos psíquicos inconscientes e a consciência é pensada no âmbito da metapsicologia. Se, por um lado, a questão acerca da natureza do psiquismo inconsciente é bastante explícita no pensamento metapsicológico freudiano, por outro, a natureza da consciência permanece consideravelmente obscura, o que nos permite dizer que a grande lacuna que permanece na teoria elaborada por Freud diz respeito à consciência.

No fim do século xıx, quando Freud começa a perceber, a partir da sua experiência clínica com as neuroses, que a identificação entre os campos do psíquico e da consciência era insuficiente para dar conta de uma série de fenômenos psíquicos, a psicologia ainda era, sobretudo, o projeto de uma ciência da consciência. As propostas de psicologia que surgem nesse período como, por exemplo, aquelas de Brentano e de William James, sustentavam a identidade entre o mental e o consciente e consideravam a existência de processos mentais inconscientes uma impossibilidade de fato e de direito (cf. James, $197^{8}$ [1890]; Brentano, 1944 [1874]). A ideia de um psíquico inconsciente não será adotada rapidamente por Freud e não aparecerá nas suas primeiras elaborações teóricas. Vários anos e textos se intercalam entre a percepção da necessidade de se supor a existência de processos inconscientes como determinantes dos sintomas neuróticos e o reconhecimento explícito de sua natureza psíquica (cf. Caropreso, 2008a).

No texto "Sobre a concepção das afasias”, de 1891, considerado por alguns autores (cf. Simanke, 2006) o passo inaugural da metapsicologia, Freud repensa o conceito de representação, a partir da crítica às hipóteses localizacionistas, então predominantes, sobre o funcionamento normal e patológico da linguagem. Ao recusar a teoria neurológica localizacionista das afasias, Freud recusa também a concepção psicológica de representação a ela subjacente, a qual se apoiava em grande medida no associacionismo de James Mill (cf. Caropreso, 2008a). Ele argumenta, nesse texto, que a representação seria o concomitante psíquico de um processo cortical associativo, ${ }^{\mathbf{l}}$ o qual consistiria na última etapa da série de reorganizações sucessivas que a informação sensorial sofreria desde o seu ingresso na medula. Aidentificação do psíquico ao consciente é ainda explicitamente mantida nesse momento. Freud afirma que os processos associativos corticais (os "correlatos" da representação) deixariam atrás de si modificações permanentes no tecido nervoso, as quais possibilitariam a repetição do mesmo processo

1 Freud adota a doutrina da concomitância defendida pelo neurologista inglês Hughlings Jackson - principal influência de Freud nesse texto de 1891 - de acordo com a qual todos os processos mentais, ou conscientes, se dariam em paralelo a certos processos cerebrais, sem que houvesse interferência causal de uma série sobre a outra (cf. Jackson, 1984[1884]]). 
INGONSGIENTE, GÉREBRo E GONSGIÊNGIA...

mediante nova estimulação - em outras palavras, permitiriam a rememoração. No entanto, uma representação só voltaria a emergir com a repetição do processo anteriormente ocorrido. A representação - e, com ela, todo o psíquico - só existiriam enquanto fatos conscientes. Diz ele: "nossa consciência não contém nada que possa justificar, do ponto de vista psicológico, o termo 'imagem latente de recordação'. No entanto, cada vez que o mesmo processo cortical volta a ser suscitado, o fenômeno psíquico anterior emerge novamente como recordação" (Freud, 1891, p.71).

Nos textos sobre as neuroses publicados nos anos seguintes, essa identidade entre o mental e o consciente começa a ser questionada. Em "As neuropsicoses de defesa" (1952 [1894]), por exemplo, Freud reconhece que é necessário supor a existência de processos inconscientes subjacentes aos sintomas neuróticos; no entanto, ele manifesta sua dúvida a respeito da legitimidade de considerá-los processos verdadeiramente psíquicos. $\mathrm{O}$ autor se pergunta, nesse texto, se os processos inconscientes não deveriam ser considerados processos puramente neurológicos, que poderiam influenciar o psiquismo, mas que não seriam, em si mesmos, psíquicos. A resposta a essa questão aparece apenas no "Projeto de uma psicologia", texto redigido em 1895, mas abandonado pelo próprio autor, tendo sido publicado apenas postumamente em 1950. Ali, Freud formula a sua hipótese do inconsciente em seu sentido "dinâmico", isto é, como constituído de processos que permanecem ativos no psiquismo embora insuscetíveis de se tornarem conscientes. ${ }^{2}$ O sentido "sistemático" do inconsciente - ou seja, do inconsciente como um tipo de processo que, além de insuscetível de consciência e efetivo, é regido por leis diferentes daquelas que governam o restante do psiquismo aparece pela primeira vez na carta a Fliess de 6 de dezembro de 1896 (Carta 52) e é desenvolvido no capítulo ₹ de "A interpretação dos sonhos" (1982a [1900]) e nos artigos sobre metapsicologia (1982b [1915]) (cf. Caropreso, 2008b).

\section{A suposição do GONGEITO DE INGONSGIENTE PSíquico}

No "Projeto de uma psicologia" (1995 [1950]), Freud passa a identificar os processos corticais - que, em 1891, eram considerados como sendo apenas os concomitantes cerebrais do psíquico - aos próprios processos psíquicos inconscientes. A consciência, que antes era pensada como um atributo de todo psíquico, passa a ser pensada como algo que acompanha apenas uma parte desses processos corticais que constituiriam o

2 Freud conclui que mesmo representações muito intensas podem permanecer insuscetíveis de consciência e preservar sua capacidade de ação no psiquismo, o que o leva a recusar a hipótese de que haveria apenas uma diferença de intensidade entre as representações suscetíveis e as insuscetíveis de se tornarem conscientes. 
psíquico inconsciente. Na seguinte passagem, Freud afirma essa expansão do campo do mental para além do da consciência:

Temos tratado os processos psíquicos como algo que possa prescindir do conhecimento dado pela consciência, existindo independentemente de tal consciência (...). Se não nos deixarmos desconcertar por tal fato, segue-se desse pressuposto que a consciência não proporciona nem conhecimento completo, nem seguro dos processos neurônicos; cabe considerá-los em primeiro lugar e em toda a extensão como inconscientes e cabe inferi-los como as outras coisas naturais (Freud, 1995 [1950], p. 187).

Freud elabora no Projeto a hipótese de um aparelho neuronal constituído por três sistemas: um sistema responsável pela recepção da excitação exógena (sistema phi), um sistema responsável pela memória (sistema psi), e um sistema responsável pela consciência (sistema ômega). Esse aparelho descreve processos que ocorreriam no sistema nervoso e que poderiam, em princípio, ser relacionados a regiões anatômicas do cérebro. Os processos representacionais, que se dariam no sistema psi, só se tornariam conscientes se uma série de condições, envolvendo também o sistema ômega, estivesse presente (cf. Simanke \& Caropreso, 2005). Mas se, por um lado, os processos corticais seriam então as próprias representações, por outro, a qualidade consciente consistiria no lado subjetivo dos processos neuronais que se dariam em ômega, como fica claro na seguinte passagem de Freud:

Segundo uma teoria mecanicista avançada, a consciência é só um aditivo aos processos fisiológico-psíquicos, cuja supressão não alteraria nada no curso psíquico. De acordo com outra doutrina, a consciência é o lado subjetivo de toda ocorrência psíquica, logo inseparável do processo fisiológico mental. Entre ambas situa-se a teoria aqui desenvolvida. Consciência é, aqui, o lado subjetivo de uma parte dos processos físicos no sistema nervoso, isto é, dos processos "ômega" (Freud, 1995 [1950], p. 190).

Portanto, a resposta que Freud encontra para a questão que ele havia levantado em "As neuropsicoses de defesa" (1952 [1894]) poderia ser formulada da seguinte forma: os processos inconscientes determinantes dos sintomas neuróticos são processos cerebrais; contudo, esses processos podem legitimamente, em função de suas características, ser considerados como "psíquicos”. Além disso, a existência desses processos psíquicos inconscientes não configura um funcionamento mental patológico, mas, ao contrário, trata-se de uma parte constitutiva de todo psiquismo, primária e, na ver- 
InGONSGIENTE, GÉREBRo E GONSGIÊNGIA...

dade, mais ampla do que aquela parte do psíquico apta a se tornar consciente. A consciência não seria uma propriedade necessária de todo mental, mas apenas uma qualidade que pode ou não vir a se acrescentar a uma pequena parte do mesmo.

A estratégia usada por Freud para incorporar em sua teoria a hipótese de processos psíquicos inconscientes teria sido identificar os processos corticais, que anteriormente haviam sido pensados como consistindo apenas nos concomitantes neurais do psiquismo, ao próprio psíquico inconsciente, deslocando, então, o paralelismo que ele antes supunha existir entre os processos neurais e o psíquico como um todo para entre o psíquico inconsciente e a consciência. Esse deslocamento do paralelismo fica mais evidente na seguinte passagem do "Esboço de Psicanálise" (1998 [1938]), um dos últimos textos escritos por Freud:

Muitos, dentro e fora da ciência, satisfazem-se em assumir que apenas a consciência é psíquica; nesse caso, nada resta para a psicologia, a não ser discriminar, nos fenômenos psíquicos, entre percepções, sentimentos, processos de pensamento e volições. Concorda-se, em geral, no entanto, que esses processos conscientes não formam séries sem lacunas, fechadas em si mesmas, de modo que não haveria outra alternativa a não ser adotar a suposição de uns processos físicos ou somáticos concomitantes do psíquico aos quais parece necessário atribuir uma perfeição maior do que às séries psíquicas, pois alguns deles têm processos conscientes paralelos e outros não. Isto sugere, de maneira natural, pôr o acento, na psicologia, sobre esses processos somáticos, reconhecer neles o psíquico genuíno e buscar uma apreciação diversa para os processos conscientes (Freud, 1998 [1938], p.157-8; grifo meu).

Nessa passagem, Freud volta a afirmar que os processos psíquicos inconscientes são processos somáticos e que a consciência seria concomitante, ou "paralela", a esses processos. Essa afirmação de Freud nos permite formular a hipótese de que, quando ele diz, no "Projeto...", que a consciência é o "lado subjetivo" dos processos corticais correspondentes ao sistema ômega, o paralelismo sustentado em 1891 está sendo deslocado para entre os processos nervosos que constituiriam o psíquico inconsciente e a consciência. Essa identificação do psíquico inconsciente a processos nervosos, sustentada em 1895 e retomada em 1938, é mantida às vezes de forma explícita, às vezes implícita, ao longo de toda a sua obra (cf. Caropreso, 2007). Sustentamos que, a partir do capítulo 7 de "A interpretação dos sonhos" (1982a [1900]), Freud passa a usar metáforas psicológicas para descrever os processos que compõem o aparelho psíquico, devido à dificuldade encontrada em dar continuidade à tentativa, iniciada no "Projeto...", de descrevê-los em termos neurológicos, mas que ele sempre considerou essa 
abordagem exclusivamente psicológica como provisória e que manteve, como horizonte de sua teorização, a crença de que sua metapsicologia poderia um dia ser substituída por uma neuropsicologia explícita (cf. Caropreso, no prelo).

\section{A justificativa do inconsciente}

Mas o que justifica a hipótese de um psíquico inconsciente nos termos em que Freud a formula? A adoção dessa hipótese impôs a Freud a necessidade de elaborar uma argumentação que justificasse a sua legitimidade. Essa argumentação não é desenvolvida de uma só vez, mas encontra-se dispersa em vários momentos da teorização freudiana, em contextos diversos, nos quais os seus vários aspectos são diferentemente ressaltados (cf. Caropreso, no prelo). Wakefield (1992) sistematiza a justificativa freudiana para a suposição de um psíquico inconsciente de forma pertinente e argumenta que, reconstruído em termos modernos, essa justificativa seria exatamente a mesma usada pelos cognitivistas contemporâneos. Wakefield observa que, em contraste com a psicologia típica das últimas décadas do século XIX, a psicologia cognitiva do fim do século xx assumiu a existência e a importância do domínio dos processos inconscientes para a explicação do pensamento e da ação, e o seu foco principal, no processo de delimitação de seu objeto e de seu campo de investigação, orientou-se para representações mentais conscientes e inconscientes. Segundo ele, a maior importância de Freud seria ter fornecido o argumento mais persuasivo, sistemático e fundamentado para essa mudança.

A sistematização da justificativa freudiana do conceito de inconsciente, proposta por Wakefield, se divide em três partes. A primeira parte do argumento envolve a seguinte questão conceitual: "mental" não significa necessariamente "consciência", ou seja, a definição do termo "mental" não requer que estados mentais sejam conscientes. A "significação" de um termo de tipo natural e a "essência” à qual esse termo se refere seriam coisas diferentes. A definição da "essência" de um termo natural caberia à investigação científica, não se tratando, pois, de uma questão puramente semântica. Por exemplo, a palavra "água” foi inicialmente definida por referência ao líquido incolor encontrado nos rios, lagos etc. Mesmo antes de se descobrir qual era a "essência" da água, foi possível inferir, a partir de certas evidências empíricas, que o gelo também era água. Posteriormente, descobriu-se a estrutura molecular da água $\left(\mathrm{H}_{2} \mathrm{O}\right)$ e esta estrutura permitiu compreender por que se tratava da mesma substância. Contudo, quando isso ocorreu, “água” não passou a significar $\mathrm{H}_{2} \mathrm{O}$. A significação do termo "água" continuou sendo, em parte, a mesma anterior, mas, a partir de então, a essência da água passou a ser conhecida como $\mathrm{H}_{2} \mathrm{O}$. Uma vez que se conhece que $\mathrm{H}_{2} \mathrm{O}$ é a 
INGONSGIENTE, GÉREBro E GONSGIÊNGIA...

essência da água, se forem encontradas outras coisas que possuam essa mesma essência, estas também poderão ser chamadas de água. Portanto, decidir quais coisas do mundo podem ser consideradas como sendo água é uma questão que deve ser estabelecida a partir da investigação científica. No entanto, mesmo antes de se descobrir qual é a essência do que é significado por um termo, é possível inferir que há outras manifestações daquela mesma essência desconhecida que também podem ser nomeadas por esse termo. Da mesma forma, o fato do termo "mental" ter sido definido primeiramente por referência a pensamentos, desejos, crenças, etc. "conscientes" não implica que só possa ser considerado mental aquilo que é consciente. "Mental" não significa “consciente", da mesma maneira como "água" não significa "líquido". Se fatos empíricos revelaram que há fenômenos com as mesmas características daquilo que se chama de mental e que não são conscientes, seria legítimo considerar esses fenômenos como sendo mentais, da mesma maneira como o foi considerar o gelo como sendo água, apesar dele não ser líquido, mesmo antes de se conhecer a estrutura molecular subjacente à água. Portanto, essa etapa da argumentação busca mostrar que não haveria obstáculo conceitual que impediria, em princípio, a suposição de uma mente inconsciente. Se há ou não justificativa para fazê-lo, seria uma outra questão que deveria ser resolvida pela investigação científica; tratar-se-ia de uma questão factual e não de uma questão semântica. Quando Freud argumenta, no texto "O inconsciente" (1982b [1915]), que a identificação do psíquico ao consciente consiste em uma convenção e que não há nenhum impedimento em abandoná-la, dado que essa convenção se revelou inadequada, ele está, de certa forma, desenvolvendo essa etapa "conceitual" da argumentação, mencionada por Wakefield.

Estabelecido que "mente inconsciente" não é uma impossibilidade conceitual, o segundo passo da argumentação é decidir se essa suposição é "teoricamente" possível, argumenta Wakefield. Para isso, em primeiro lugar, é preciso definir qual é a essência do mental e, então, estabelecer se coisas com essa essência podem ser inconscientes. É claro que, caso se parta do pressuposto de que a consciência seja a essência do mental, supor que há mente inconsciente seria um contra-senso; contudo, para Freud, a consciência não constituiria a essência do mental. Wakefield argumenta que a essência do mental seria, para ele, a representacionalidade dos estados cerebrais e que esta seria uma propriedade que poderia ser aplicada a estados cerebrais não conscientes. De fato, desde o "Projeto de uma psicologia", Freud desenvolve a hipótese de que o mental é, sobretudo, o representacional - isto é, processos cerebrais com características específicas que se referem a um objeto, a um estímulo corporal a uma palavra - e que a consciência é apenas uma qualidade que pode ou não se acrescentar a uma representação. 
Wakefield observa que a postulação de uma essência é, em grande parte, a postulação de uma causa subjacente ao fenômeno manifesto, a partir do qual a categoria foi selecionada em primeiro lugar. Por exemplo, o movimento de elétrons é a essência da eletricidade, porque os fenômenos que primeiramente foram nomeados como eletricidade são, em última instância, explicáveis pelo processo subjacente do movimento de elétrons. Uma vez que este movimento tenha sido estabelecido como a essência do fenômeno especificado, qualquer outro processo que tenha a mesma essência pode ser legitimamente categorizado como eletricidade. Mas, mesmo antes da essência ser conhecida, um fenômeno podia ser descoberto como fazendo parte da categoria eletricidade, a partir de evidências indiretas de que ele compartilha a mesma essência do fenômeno original. Wakefield argumenta que, assim como a maioria dos cientistas cognitivos atuais, Freud acreditava que o fator explicativo relevante do mental é a estrutura representacional dos estados cerebrais, independentemente do estatuto consciente ou não desses estados. A consciência seria apenas algo que se poderia acrescentar a um estado cerebral com estrutura representacional. Esta estrutura seria a essência "provisória" do mental e seria independente da consciência.

Wakefield chama a atenção para o fato de que Freud, assim como os cientistas da cognição atuais, estava ciente de que considerar a representacionalidade dos estados cerebrais a essência do mental era uma postura provisória e que uma resposta real sobre essa essência requereria uma especificação detalhada da natureza do sistema representacional do cérebro. No texto "Algumas lições elementares sobre psicanálise" (1998 [1938]), Freud deixa isso claro. Nesse sentido, nem ele, nem os cientistas cognitivos, supõem terem chegado já a realmente conhecer a essência do mental.

Então, seria teoricamente possível conceber uma mente inconsciente, porque se parte do pressuposto de que a essência "provisória" do mental - a representacionalidade dos estados cerebrais - pode se realizar na ausência da consciência. Essa essência só seria, de fato, inteiramente compreendida quando fosse possível especificar as características dos estados cerebrais que lhes conferem sua representacionalidade. Mas, mesmo antes de se alcançar esse esclarecimento, seria legítimo supor que a consciência não é uma propriedade inerente a todo o mental e, portanto, seria teoricamente legítima a suposição de uma mente inconsciente.

A terceira etapa da argumentação consiste em estabelecer se estados mentais inconscientes não são apenas conceitualmente e teoricamente possíveis, mas existem realmente. Desde o início de suas investigações sobre as neuroses, Freud se deparou com fenômenos que podiam ser tomados como evidências empíricas da existência de processos mentais inconscientes: a sugestão pós-hipnótica, os sintomas neuróticos, os sonhos, os atos falhos, e tantos outros. Wakefield comenta que os estudos de caso de Freud constituem longos argumentos a favor da necessidade de se postular represen- 
INGONSGIENTE, GÉREBRo E GONSGIÊNGIA...

tações inconscientes para explicar o pensamento e o comportamento dos pacientes. Na verdade, a evidência empírica de que há processos mentais inconscientes foi o ponto de partida de toda a investigação freudiana.

Além das etapas descritas por Wakefield e retomadas acima, Freud dá muita ênfase em sua argumentação para justificar o inconsciente ao fato de que a suposição de uma mente inconsciente é condição para que a psicologia possa se configurar como uma ciência natural, dado que os fenômenos conscientes são lacunares e não podem ser explicados causalmente sem a suposição de processos inconscientes - o que podemos chamar de uma justificativa heurística - e também desenvolve o que podemos chamar de uma justificação pragmática da suposição do inconsciente, quando alega que, a partir dela, foi possível criar um procedimento clínico de intervenção eficaz. Essas justificações heurística e pragmática seriam, na verdade, desdobramentos da parte empírica da argumentação, tal como esta se encontra na sistematização de Wakefield, as quais não são analisadas separadamente por esse autor.

\section{O PROBLEMA DA GONSGIÊNGIA}

Se, por um lado, a natureza física do psíquico inconsciente é claramente afirmada por Freud, a questão a respeito da natureza dos processos psíquicos conscientes e da relação entre o psíquico inconsciente e o consciente permanece bastante obscura no pensamento freudiano. Já no "Projeto de uma psicologia”, e em diversos de seus textos metapsicológicos posteriores, Freud se preocupa em estabelecer quais seriam as condições que os processos psíquicos teriam que satisfazer para poderem ser apreendidos conscientemente. Ele formula a hipótese de que para que um processo perceptivo se tornasse consciente seria necessário que ele despertasse "sinais de qualidade" e que os mesmos fossem focalizados pelo mecanismo da "atenção". A rememoração, por outro lado, dependeria da associação com representações de palavra, ou seja, com a linguagem. Enfim, Freud formula uma série de hipóteses sobre as condições de possibilidade da consciência, ao mesmo tempo em que afirma que esta seria o "lado subjetivo" ou seria "concomitante" aos processos psíquicos inconscientes, os quais, em última instância, consistiriam em processos cerebrais com certa organização específica. Isso faz com que a questão mente-cérebro tenha que ser pensada em duas etapas na teoria freudiana. Por um lado, há a relação entre os processos psíquicos inconscientes e os processos cerebrais e essa seria uma relação de identidade, dado que Freud afirma explicitamente que os processos psíquicos inconscientes são processos nervosos. Dada certa organização dos processos cerebrais, estes adquiririam propriedades que poderiam ser chamadas de mentais. Por outro lado, há a relação entre esses processos psí- 
quicos inconscientes e a consciência. Seriam os fenômenos conscientes "concomitantes" ao psíquico inconsciente e de natureza distinta dos processos físicos, de forma que Freud teria trazido o dualismo substancial para dentro do campo do psíquico? O seguinte comentário de Chomsky é pertinente em relação ao problema em questão:

Nós não somos forçados, como o foi Descartes, a postular uma segunda substância quando lidamos com fenômenos que não podem ser expressos em termos de matéria em movimento (...). É uma questão interessante saber se o funcionamento e a evolução da mentalidade humana podem ser acomodados dentro do esquema das explicações físicas, assim como é entendido atualmente, ou se existem princípios novos, agora desconhecidos, que precisam ser revelados, talvez princípios que surgem apenas em níveis mais altos de organização do que os que agora podem ser submetidos à investigação física (Chomsky apud Nagel, 1976, p. 35 ).

A afirmação de Freud de que a consciência seria concomitante aos processos somáticos inconscientes seria apenas uma maneira encontrada por ele para não se comprometer com a questão sobre a natureza da consciência? A impossibilidade de explicar a consciência em termos de processos físicos seria, a seu ver, uma impossibilidade definitiva ou provisória? Todas essas questões permanecem em aberto no pensamento freudiano, pois em momento algum ele esclarece em que exatamente estava pensando quando dizia que a consciência é o "lado subjetivo" ou é "concomitante" aos processos cerebrais que constituem o psíquico inconsciente. ${ }^{3}$

\section{Conclusão}

A estratégia usada por Freud para incorporar em sua teoria a ideia de um psiquismo inconsciente parece ter sido, então, identificar este último a processos cerebrais com certa organização específica e deslocar o paralelismo sustentado em "Sobre a concepção das afasias" para entre os processos psíquicos inconscientes e a consciência, de maneira que temos, na teoria freudiana, tanto um problema mente-cérebro, quanto um "problema mente-mente" (cf. Simanke, no prelo). Isso levou Freud a instaurar uma cisão dentro do campo da psicologia entre uma psicologia do inconsciente e uma

3 Thomas Nagel faz o seguinte comentário, pouco esclarecedor, a esse respeito: "dizer que a consciência é o "lado subjetivo" de um certo tipo de processo neurofisiológico não é compatível com o dualismo, mas também pode ser um erro chamar isso de materialismo" (Nagel, 1976, p. 32). 
psicologia da consciência. A primeira, a seu ver, seria uma ciência natural que teria como objeto de estudo processos cerebrais com certas propriedades específicas, os quais um dia poderiam vir a ser explicados enquanto tais (por uma teoria neurobiológica da mente, por exemplo). Sua metapsicologia consistiria, assim, em uma tentativa de teorizar sobre esses processos usando, provisoriamente, metáforas e modelos psicológicos. Essa metapsicologia inclui, é verdade, uma reflexão sobre as condições de possibilidade da consciência, mas não entra na questão sobre como certos processos cerebrais poderiam dar origem à qualidade que caracteriza a experiência consciente, nem se isso seria possível - ou seja, se as qualidades sensoriais seriam ou não produtos de processos cerebrais. Freud não se compromete com afirmações ontológicas a respeito da consciência, provavelmente por estar ciente das enormes dificuldades que essa questão envolve. Essa é uma das grandes lacunas que permanecem na sua teoria, o que, entre outros motivos, coloca seu pensamento em uma situação bastante próxima ao contexto atual da filosofia da mente e da ciência cognitiva, para as quais a questão da relação entre o cérebro e a consciência ainda se coloca como um grande enigma.

\title{
Fátima Caropreso
}

Professora da Faculdade de Ciências Humanas, Universidade Federal da Grande Dourados, Brasil.

fatimacaropreso@uol.com.br

\begin{abstract}
In the late $19^{\text {th }}$ century, when Freud initially realized that the identification between mind and consciousness could not account for a series of psychic phenomena, psychology was the project for a science of consciousness yet. The programs for a scientific psychology emerging at that time, such as Brentano's, Wundt's and James', sustained the identity of mind and consciousness and regarded the existence of unconscious mental processes as a factual and theoretical impossibility. Firstly, this paper sets out to discuss Freud's strategy to formulate the hypothesis of an unconscious psychical in his metapsychological theory. Next, it examines the justification of this hypothesis, following the systematic reconstruction of Freud's argument suggested by J. Wakefield (1992). Lastly, it briefly comments on the relationship between conscious and unconscious psychic processes, such as it is presented in Freudian metapsychology, stressing how this relationship turns out to be one of its greatest theoretical difficulties.
\end{abstract}

KEYwords • Freud. Metapsychology. Unconscious. Consciousness. Brain processes. 


\section{REFERÊNGIAS BIBLIOGRÁFICAS}

Aires, S. \& Ribeiro, C. (Org.). Ensaios de filosofia e psicanálise. Campinas: Mercado de Letras, 2008.

Barron, J. W. et al. (Org.). Interface of psychoanalysis and psychology. Washington: American Psychological Association, 1992.

Brentano, F. Psychologie du point de vue empirique. Paris: Aubier, 1944 [1874].

Caropreso, F. Metapsicologia, psicologia, neuropsicologia: considerações acerca do sentido da reflexão metapsicológica no pensamento freudiano. Representaciones, 3, 2, p.25-4,2, 2007.

. O nascimento da metapsicologia: representação e consciência na obra inicial de Freud. São Carlos:

Edufscar, 2008a.

O inconsciente psíquico na metapsicologia freudiana: desenvolvimento e articulações conceituais.

In: Aires, S. \& Riberro, C. (Org.). Ensaios de filosofia e psicanálise. Campinas: Mercado de Letras, 2008b. p. 107-28.

. Freud e a natureza do psíquico: o sentido da metapsicologia na psicanálise freudiana. São Paulo: AnnaBlume/Fapesp. No prelo.

Freud, S. Zur Auffassung der Aphasien: eine Kritische Studie. Leipzig: Franz Deuticke, 1891.

Gesammelte Werke. London: Imago, 1952-1972, 18 v.

Die Abwehr-Neuropsychosen. In:___. Gesammelte Werke. London: Imago, $195_{2}^{2}$ [1894] v. 1. p. 57-74.

Die Traumdeutung. In: Mitscherlich, A.; Richards, A. \& Strachey, J. (Ed.). Studienausgabe. Frankfurt am Main: Fischer Taschenbuch Verlag, 1982a [1900]. v. 2.

. Das Unbewusste. In: Mitscherlich, A.; Richards, A. \& Straghey, J. (Ed.). Studienausgabe. Frankfurt am Main: Fischer Taschenbuch Verlag, 1982b [1915].v. 3. p. 119-62.

Projeto de uma psicologia. Rio de Janeiro: Imago, 1995 [1950].

. Esquema del psicoanálisis. In: Moisés y la religión monoteísta, esquema del psicoanálisis yotras obras. Buenos Aires: Amorrortu, 1998 [1938]. p. 133-210. (Obras Completas de Sigmund Freud, 23)

Jackson, J. H. Evolution and dissolution of the nervous system. In: TAYLOR, J. (Org.). Select writings of John Hughlings Jackson. New York: Basic Books, 1984, [1884]. p. 45-118.

James, W. The principles of psychology. London: Encyclopaedia Britannica, 1978 [189o].

Mauro, C.; Miguens, S. \& Gadilha, S. (Org.). Mente e ação: artigos para a discussão. Porto: Campo de Letras. No prelo.

Mitscherlich, A.; Righards, A. \& Strachey, J. (Ed.). Studienausgabe. Frankfurt am Main: Fischer Taschenbuch Verlag, 1969-1989. $10 \mathrm{v}$.

Naged, T. O antropomorfismo de Freud. In: Wollheim, R. (Org.). Freud: uma coletânea de ensaios críticos. Rio de Janeiro: Artenova, 1976. p. 25-38.

Simanke, R. T. Cérebro, percepção e linguagem: elementos para uma metapsicologia da representação em "Sobre a concepção das afasias" (1891). Discurso, Revista do Departamento de Filosofia da USP, 36, p. 55-94, 2006.

. O problema mente-mente e o problema mente-corpo da metapsicologia: a lacuna explicativa na psicanálise freudiana. In: Mauro, G.; Miguens, S. \& Cadilha, S. (Org.). Mente e ação: artigos para a discussão. Porto: Campo de Letras. No prelo.

Simanke, R. T. \& Caropreso, F. O conceito de consciência no "Projeto de uma psicologia" de Freud e suas implicações metapsicológicas. Trans/form/ação, 28, 1, p. 85-108, 2005.

TAYLOR, J. (Org.). Select writings of John Hughlings Jackson. New York: Basic Books, 1984.

WAKEFIELD, J. C. Freud and cognitive psychology: the conceptual interface. In: BARRon, J. W. et al. (Org.). Interface of psychoanalysis and psychology. Washington: American Psychological Association, 1992. p. 77-98.

Wollheim, R. (Org.). Freud: uma coletânea de ensaios críticos. Rio de Janeiro: Artenova, 1976. t. 1. 